[DOI: 10.24214/jecet.A.8.1.07283]

Jaurnal of Environmental Science, Computer Science and Engineering \& Technology

An International Peer Review E-3 Journal of Sciences and Technology

Available online at www.jecet.org

Section A: Environmental Science

Research Article

\title{
Agrochemicals use on carrot (Daucus carota) cultivation and its phytochemicals content at Kedjom-Ketinguh, North- West, Cameroon
}

\author{
*Sonchieu Jean ${ }^{1}$, Feh Watad Gilbert ${ }^{1}$, Fru Nsoh John ${ }^{1}$ \\ ${ }^{1}$ Department of Social Economy and Family Management, Higher Technical Teacher Training College, \\ The University of Bamenda, P.O. Box, 39 Bamenda, Cameroon
}

Received: 20 December 2018; Revised: 08 January 2019; Accepted: 16 January 2019

\begin{abstract}
Nationwide surveys conducted on pesticide application in Cameroon raised growing concern of the exposure of applicators. The aim of this study was to investigate the agricultural practices in carrot cultivation, phytochemical composition of carrot and the various exposures of farmers associated with the use of agrochemicals in the cultivation of carrot in Kedjom-Ketinguh, Tubah Sub-Division (North-West Region, Cameroon). A questionnaire was randomly administered to 100 carrot cultivation farmers for a period of twelve months. Laboratory analysis was done to determine the content of carrot with flavonoids, total carbohydrates and phenolic acid using spectrophotometric technics. The results obtained indicate that: $95 \%$ of the farmers use chemical fertilizers and organic manure (cow dung and fowls drops); $34 \%$ of farmers use fungicide such as pencozeb, mancozeb and plantineb, which are bought in local market or from individuals and stored in rooms in the house; the planting is done in March at 50\%, some minor health hazards associated with the use of agrochemicals were observed; the concentration of carbohydrates, flavonoids and phenols varies from the control to treated samples. The carrot produced in Kedjom-Ketinguh may be considered safe for consumption looking at the pesticide use and the quality is improved with the use of organic fertilizers.
\end{abstract}

Key Words: Agricultural Practices, Agrochemicals, Phytochemicals, Survey, Carrot

\section{INTRODUCTION}

The interest of consumption of organic food, including vegetables, has been on a steady increase within the last decades in many countries in the world ${ }^{1}{ }^{3}$. Vegetables and fruits are important sources of 
vitamins, minerals, trace elements, dietary fiber and a large variety of beneficial phytochemicals, which might decrease the risk of certain age-related and cardiovascular diseases. Therefore, the dietary guidelines recommend eating at least five portions of fruits and vegetables a day ${ }^{4}$ Carrots are among the most popular root vegetables consumed in Cameroon but little produced ${ }^{5}$. It is the most important crop of the Apiaceae (Umbelliferae) family characterized by small, mostly white, 5-parted flowers arranged in umbrella-like inflorescence called umbel ${ }^{6}$.Carrots were first used for medical purposes and gradually used as food ${ }^{7}$. This vegetable is an important source of bioactive compounds with beneficial effect for the consumer's health. Carrots are consumed in different ways; they can be eaten raw or cooked. In the agricultural sector, they are important in the supply of raw materials to the agro-based industries, employment for people and generation of foreign exchange among others ${ }^{8}$.

Carrots are good source of carbohydrates and minerals like calcium, potassium, iron and magnesium ${ }^{9}$. This root vegetable contains valuable phytochemicals and is very rich in antioxidants, especially $\beta$-carotene and some amount of flavonoids and phenols. In recent years, worldwide consumption of carrots has been steadily increasing because of their nutritional benefits. Carrots have potential beneficial health effects such as anti-carcinogenic, antioxidant, and immune boosting properties, as well as the pro-vitamin A activity of some carotenoids ${ }^{10}$. In addition, carrots have the ability to improve the quality of the skin, digestion, cardiovascular health, to detoxify the body, and boost oral health in a variety of ways ${ }^{11}$. Carrot is one of the most important vegetable cultivated in many parts in the North-West Region of Cameroon such as Santa, Bambui, Sabga and Small-Babanki. The nutritive and energetic values of carrots vary to a considerable extent depending on the origin (environmental factors) and the type of fertilizer used in its cultivation ${ }^{12,13}$.

Heavy use of synthetic pesticides in agriculture worldwide has raised serious concerns about health issues. The WHO estimates that acute pesticide poisoning (APP) affects three million people and accounts for twenty thousand unintentional deaths per year, with $99 \%$ of these fatalities believed to be in developing countries ${ }^{14}$. There is therefore need for a systematic study to investigate the potential link of agricultural practices on the chemical composition of carrot and the potential exposures of farmers associated with the use of agrochemicals in the cultivation of carrot in Kedjom- Ketinguh, Tubah SubDivision. The production of carrot has been done for decades but no scientific study has been conducted on the use of neither agrochemical nor the phytochemical content. Furthermore this vegetable is considered as secondary rank produce. So less importance is given to it. The objective of this work is then to investigate on agricultural practices applied by farmers and phytochemical content of carrot produced. Results may be used to valorize the locally produced carrot, which at certain extent can help in solving deficiencies of vitamin A noticed by $\mathrm{WHO}^{15}$ in Cameroon.

\section{MATERIALS AND METHODS}

2.1 Study Area: This study was carried out in Kedjom Ketinguh situated in Tubah Sub-Division (Mezam Division, North West Region, Cameroon). According to the geographical coordinates, the said area is located between latitude $5^{\circ} 66^{\prime}$ and $6^{0} 15^{\prime}$ north of the equator and longitudes $9^{0} 55^{\prime}$ and $10^{\circ} 22^{\prime}$ east of the Greenwich Meridian ${ }^{16}$. Carrot produced here is among other foods such as onion, tomato and garlic is supplied to Bamenda (main city of the Region) and at time exported to other main cities of Cameroon such as Douala and Yaoundé. According to the National Institute of the Statistics of Cameroon (INSC) ${ }^{5}$, this small locality which covers a surface area of about $25 \mathrm{~km}^{2}$ is inhabited by about 17,000 people who are $90 \%$ farmers. According to observations done on the field, the production is not negligible since there no statistics available from the Ministry of Agriculture and Rural Development ${ }^{5}$ as compared to other zones where carrot is being produced in the North-West Region. 
2.2 Data Collection Methods: A total of 100 farmers who are specialized in the production of carrot were systematically sampled and data collected by field observations, and through questionnaire or interviews. The questionnaire (made up of both closed-ended and open-ended questions) was divided into three parts: part one comprises the demographic information; part two was on methods of cultivation and agrochemicals uses, and the last part (three) focused on health implications linked to the use of agrochemicals. The study was carried out for 12 (twelve) months (from November 2016 to October 2017) and farms were visited monthly.

\subsection{Laboratory Analysis}

2.3.1 Reagents and instrumentation: Samples were weighed using an electronic laboratory scale (G and $\mathrm{G}$ ) and the following components were quantified through UV-visible spectrophotometer (Model 752): carbohydrates, flavonoids and phenols. Reagents used were: Gallic acid, Folin Ciocalteu reagent, sodium carbonate and quercetin obtained from Sigma Aldrich (France), while potassium acetate and aluminum chloride were purchased from Burgoynes and Co. (Mumbai, India) and pure methanol obtained from LabalChemie (Mumbai, India). Extracts were sedimented using a centrifuge (Hettich EBA3S). Carrot used was randomly collected both from treated and untreated farms (for control).

2.3.2 Extraction and Quantification of carbohydrates: The method that was used was the Phenolsulphuric acid method with glucose as its standard. Carrots were grated and $0.5 \mathrm{~g}$ of the different paste samples was weighed and dissolved into $10 \mathrm{~mL}$ of the phosphate buffer in a mortar to get a concentration of $50 \mathrm{mg} / \mathrm{mL}$. The mixture was then transferred into a plastic test tube and was used for the analysis of carbohydrates.

Each of the different samples was prepared in duplicates. $0.6 \mathrm{~mL}$ of each extract was put in a dry and clean test tube with the help of a micropipette. $1.4 \mathrm{~mL}$ of distilled water and $1 \mathrm{~mL}$ of concentrated sulphuric acid was added in each tube, and then incubated in a water bath at $40{ }^{\circ} \mathrm{C}$ for 15 minutes. They were allowed to cool at room temperature for 10 minutes after incubation. $0.2 \mathrm{~mL}$ of $6 \%$ phenol was added in each test tube, homogenized by shaking and allowed for $1 \mathrm{~min}$. The test tubes were taken to the analysis table where the optical densities at $480 \mathrm{~nm}$ were read in the UV-VIS spectrophotometer (model 752). These optical densities were then used to calculate the concentration of carbohydrate in each sample. That is it was deduced using the standard curve of glucose.

2.3.3 Extraction and Quantification of Flavonoids: Each plant sample $(1 \mathrm{~g})$ was macerated in $5 \mathrm{~mL}$ of 95\% methanol. The mixture was then allowed to stand in a dark cupboard for $72 \mathrm{~h}$, filtered with filter paper (Whatman, no. 1) and centrifuged (3500 rpm, $10 \mathrm{~min}, 25^{\circ} \mathrm{C}$ ) and the supernatant collected. The total flavonoid content was determined in the supernatant by the aluminum chloride colorimetric assay as described by Kamtekar et al. ${ }^{17}$ using quercetinas the standard. Briefly, $0.1 \mathrm{~mL}$ of the $1 \mathrm{M}$ potassium acetate was added to $0.3 \mathrm{~mL}$ of extracts and the mixture incubated at room temperature for $5 \mathrm{~min}$. Then, $0.1 \mathrm{~mL}$ of $10 \%$ aluminum chloride was added and the volume made up to $3.5 \mathrm{ml}$ with distilled water. After homogenization, the mixture was incubated for $15 \mathrm{~min}$ at room temperature for color development and the absorbance measured at $415 \mathrm{~nm}$ against the blank using a spectrophotometer. The total flavonoids content of samples were expressed as $\mu \mathrm{g}$ of quercetin equivalents per $1 \mathrm{~g}$ of each fresh carrot ( $\mu \mathrm{g} \mathrm{QE} / \mathrm{g}$ of carrot) from quercetin calibration curve (concentrations: 0.05 to $0.50 \mu \mathrm{g} / \mathrm{mL}$ ).

2.3.4 Determination of the total phenolic compounds: One gram of each sample was weighed and ground in a mortar, then, $15 \mathrm{~mL}$ of $95 \%$ methanol was added to each tube and after homogenization the samples were kept in a dark place for $24 \mathrm{~h}$ with intermittent shaking to optimize the extraction. Samples were then filtered with filter paper Whatman no. 1, the filtrate was then centrifuged ( $3500 \mathrm{rpm}, 10 \mathrm{~min}$, 
$25^{\circ} \mathrm{C}$ ) and the supernatant collected for the quantification of the total phenolic content using Folin Ciocalteu's method as described by Tchouya and Nantia ${ }^{18}$. Briefly, $0.9 \mathrm{ml}$ of $95 \%$ methanol and $0.1 \mathrm{~mL}$ Folin reagent were added to $0.1 \mathrm{~mL}$ of each extract. After homogenization, the mixture was incubated at room temperature for $5 \mathrm{~min} ; 1 \mathrm{~mL}$ of $20 \%$ sodium carbonate and $0.5 \mathrm{~mL}$ of distilled water were thereafter added and the mixture made up to $2.6 \mathrm{~mL}$ with distilled water. The reaction was then allowed to develop for $15 \mathrm{~min}$ at room temperature and the absorbance measured at $750 \mathrm{~nm}$ using a UV-Vis spectrophotometer. The total phenolic content in each sample was expressed as mg of Gallic Acid Equivalent per gram of carrot sample (mg GAE/ $\mathrm{g}$ of carrot) using standard gallic acid calibration graph (concentrations: 0.005 to $0.03 \mathrm{mg} / \mathrm{mL}$ ).

2.4. Statistical Analysis: Data collected from questionnaires were analyzed using descriptive statistics and comparison done using frequencies. For biochemical analyses, differences between treated samples were assessed using one factor ANOVA followed by the Student-Newman-Keuls test. The P-values less than 0.05 were considered statistically significant. All analyses were performed using SPSS 17.0 software. Data represented are mean with the standard deviation (mean \pm SD) of 3 independent experiments. A descriptive statistical analysis was done to generate frequencies and tables. A nonparametric test, Chi square test, was performed to identify possible associations with a p-value of $<0.05$ considered to be statistically significant.

\section{RESULTS}

3.1 Demographic Information on Respondents: Table 1 below gives background information of the respondents in term of the sex, marital status, age, educational status, training and other factors related to cropping of carrot.

From Table 1, more farmers are males (64\%). A statistical difference was not observed among males and females $\left(\chi^{2}=0.00 ; p=1\right)$. They are generally married and are head of families. Chi square test doesn't show any statistical significant difference with value of $3.250(p=0.500)$. Their age distribution shows that, the most representative age range is between $31-40$ years old, with the men dominating in this group.

The level of education is very poor and shows that $94 \%$ of carrot farmers are primary school graduates. Statistically, there was no significance difference according to the level of education or the age groups $\left(\chi^{2}=5.75 ; p=0.21\right)$ between groups. They are not assisted by any qualified technician and have never undergone any training neither for long nor short terms. Statistically no significant difference was observed and chi-square and $p$-value were identical $\left(\chi^{2}=3.25 ; \mathrm{p}=0.50\right)$. In this context carrot is cultivated only for market but can still be eaten by family members or workers at very little amount.

A good number of them use fertilizers (66\%) but a lesser number invest in using pesticides during cropping. Many of the farmers have more than ten years of experience based on this activity. It was noticed that the only cultivated variety is the commonly known technisem (orange colored type). The use of fertilizers, pesticides and the number of years of experience did not show any significant difference and presented equal $p$-value and chi-square $\left(\chi^{2}=3.25 ; \mathrm{p}=0.50\right)$. The no significant difference obtained here indicates that farmers have similar way of farming. This testifies also their collaboration in the localities in producing carrot. 
Table1: Demographic data and some general information on cropping

\begin{tabular}{llll}
\hline \multirow{2}{*}{ Considerations } & & & Chi-square/ \\
Sex & Male & Frequency $(\%)$ & p-value \\
Marital status & Female & $36(36)$ & $\chi^{2}$-value $=0.00$ \\
& Single & $2(2)$ & p-value $=1$ \\
Age range & Married & $98(98)$ & $\chi^{2}$-value $=3.25$ \\
p-value $=0.50$
\end{tabular}

FSLC: First School Leaving Certificate, GCE-O/L: General Certificate of Education Ordinary Level, GCEA/L: General Certificate of Education Advanced Level

3.2 Agricultural practices in carrot cultivation: The parameters considered vary from areas exploited, planting season, varieties cultivated and the number of years of experience. During the one year investigation, it was observed that cultivation of carrot is done on upland. Table 2 below indicates some parameters of the cultivation of carrot in the study area.

It can be noticed that planting is mostly done during rainy season (March-September, 62\%) while less farmers plant carrot during dry season (November-February, 38\%). The period of harvesting depends then on the planting season which is generally four months after or more depending on the availability of clients or prices in the markets. The months of February and March (62\%) are planting period and this coincides with the starting of the agricultural campaign. Very few people are interested with the dry season harvesting of carrot. Statistically, there was a significance difference obtained in the variation of season or between seasons $\left(\chi^{2}=22.375 ; \mathrm{p}=0.00\right)$. This is to show the cultivation of carrot through the year. 
Table 2: Planting and harvesting season

\begin{tabular}{lllll}
\hline Seasons & Period & Planting frequency $(\%)$ & Harvesting frequency $(\%)$ & $\begin{array}{l}\text { Chi-square/ } \\
\text { p-value }\end{array}$ \\
\hline \multirow{2}{*}{ Dry season } & November & $4(4)$ & $2(2)$ & $\chi^{2}$-value $=22.375$ \\
& Dec & $10(10)$ & $6(6)$ & p-value=0.00 \\
& January & $4(4)$ & $2(2)$ & \\
& February & $12(12)$ & $4(4)$ & \\
& March & $50(50)$ & $12(12)$ & $\chi^{2}$-value $=22.375$ \\
Rainy & April & $2(2)$ & $2(2)$ & p-value $=0.00$ \\
season & May & $0(0)$ & $8(8)$ & \\
& June & $2(2)$ & $44(44)$ & \\
& July & $4(4)$ & $14(14)$ & \\
& August & $2(2)$ & $2(2)$ & \\
& September & $6(6)$ & $0(0)$ & \\
\hline
\end{tabular}

3.3 The use of Fertilizers and some influencing factors: The enhancement of carrot productivity depends on the use of fertilizers. These may be organic or inorganic. Table 3 shows the different types of fertilizers used by farmers, the purpose and duration of usage.

Table 3: Use of fertilizers with some factors

\begin{tabular}{llll}
\hline Factors & & Frequency $(\%)$ & $\begin{array}{l}\text { Chi-square/ } \\
\text { p-value }\end{array}$ \\
\hline Inorganic fertilizers & NPK (20:10:10) & $16(20)$ & \\
& Urea & $60(73)$ & $\chi^{2}$-value $=0.750$ \\
& Sulphate & $6(7)$ & -value $=1.000$ \\
Organic fertilizers & Cow dung & $1(20)$ & $\chi^{2}$-value $=0.750$ \\
(manure) & Fowl drops & $4(80)$ & p-value $=1.000$ \\
Purpose of using fertilizer & Increasing crop yield & $72(88)$ & \\
& Improving soil fertility & $4(5)$ & $\chi^{2}$-value $=0.667$ \\
& crop protection & $4(5)$ & p-value $=1.000$ \\
Experience in fertilizers & Others & $2(2)$ & \\
use (years) & $<1$ & $4(5)$ & $\chi^{2}$-value $=0.667$ \\
& {$[2-9]$} & $38(46)$ & p-value $=1.000$ \\
\hline
\end{tabular}

Table 3 above shows that only five farmers (5\%) use organic fertilizers collected from fowl droppings and cow dung; while 95\% use inorganic fertilizers such as urea, Nitrogen-Phosphate-Potassium combination (20\%-10\%-10\% respectively) and sulphate. Reasons given in using fertilizer is to increase crop yield, to ameliorate the soil fertility and for crop protection. Furthermore, the farmers have great experience in using fertilizers which varies from one to more than ten years. No statistically difference was obtained either between type of fertilizers used (organic or inorganic), nor for the purpose or the number of year spent in using fertilizers. Chi square values were similar for all the parameters, emphasizing the similarities between agricultural practices and famers behaviors. 
3.4 The use of Pesticides and farmer's knowledge: Different types of pesticides used in the cultivation of carrot in Kedjom-Ketinguh, the awareness on government approval and the frequency of usage were looked at. The use and storage parameters of pesticides that can influence the health of applicators are shown in the Table 4.

Table 4: The use of pesticides and perception

\begin{tabular}{|c|c|c|c|}
\hline Considerations & & $\begin{array}{l}\text { Frequency } \\
(\%)\end{array}$ & $\begin{array}{c}\text { Chi-square/ } \\
\text { p-value }\end{array}$ \\
\hline \multirow{4}{*}{ Pesticides used } & Pencozeb (fungicide) & $22(22)$ & \\
\hline & Plantizeb (fungicide) & $8(8)$ & $\chi^{2}$-value $=0.297$ \\
\hline & Mancozeb (fungicide) & $4(4)$ & $\mathrm{p}$-value $=6.475$ \\
\hline & None & $66(66)$ & \\
\hline \multirow[t]{2}{*}{ Reasons of use } & Diseases & $32(94)$ & $\chi^{2}$-value $=3.258$ \\
\hline & Pests & $2(6)$ & $\mathrm{p}$-value $=0.750$ \\
\hline \multirow{3}{*}{$\begin{array}{l}\text { Awareness of approval of } \\
\text { pesticide }\end{array}$} & Yes & $2(2)$ & $\chi^{2}$-value $=3.258$ \\
\hline & No idea & $32(32)$ & $\mathrm{p}$-value $=0.750$ \\
\hline & Once & $16(47)$ & \\
\hline \multirow{2}{*}{$\begin{array}{l}\text { Number of treatment / } \\
\text { cycle }\end{array}$} & Twice & $4(12)$ & $\chi^{2}$-value $=3.258$ \\
\hline & $>2$ times & $14(41)$ & $\mathrm{p}$-value $=0.750$ \\
\hline \multirow{4}{*}{$\begin{array}{l}\text { Influence of weather on } \\
\text { treatment and doses }\end{array}$} & Yes & $32(32)$ & \\
\hline & No & $2(2)$ & $\chi^{2}$-value $=3.258$ \\
\hline & Doses (no) & $34(100)$ & $\mathrm{p}$-value $=0.750$ \\
\hline & Retailers farmers' House & $6(18)$ & \\
\hline \multirow[t]{3}{*}{ Suppliers } & Retailers' shops in the community & $10(29)$ & $\chi^{2}$-value $=7.750$ \\
\hline & Kedjom-Ketinguh market & $18(53)$ & $\mathrm{p}$-value $=0.188$ \\
\hline & Special room at home & $22(65)$ & $\chi^{2}$-value $=7.750$ \\
\hline \multirow[t]{2}{*}{ Storing area } & Hut in the farm & $10(29)$ & $\mathrm{p}$-value $=0.188$ \\
\hline & Special bag at Home & $2(6)$ & \\
\hline Number of treatment & $<2$ & 20(59) & $\chi^{2}$-value $=7.750$ \\
\hline \multirow[t]{2}{*}{ Before harvesting } & {$[2-3]$} & $8(24)$ & $\mathrm{p}$-value $=0.188$ \\
\hline & $>4$ & $6(18)$ & \\
\hline
\end{tabular}

Table 4 shows that only $34 \%$ of sampled farmers use pesticides to protect carrot from pests and diseases while the remaining does not use them. Only fungicides are used and include pencozeb, mancozeb and plantizeb. Two main reasons being that, these plants protection substances are against diseases and to fight pests. Which is a wrong concept as it is known that these are fungicides. Statistics did not show any significance differences of fungicides use $\left(\chi^{2}=297 ; \mathrm{P}=6.475\right)$. This indicates that the fungicides are equally used by farmers of the study area. This can be understood since all have the same effectiveness. Among the users, up to Thirty-two (32) of the farmers did not have knowledge about the homologation of the chemical by the government. They just apply it because they want to protect their crops no matter whether it is authorized or not. No statistical significance differences were gotten between various factors of perception for using fungicides such as homologation rules or the reasons of application $\left(\chi^{2}=\right.$ 3.258; $\mathrm{P}=0.750$ ).

The chemicals are obtained from local market, individuals (colleagues or relatives who retail) or from the community shops which sell in reconditioned containers or in small quantity (100 grams, 500 grams and 1000 grams). The chemicals were generally stored in the house in bags or in a special space and at 
times in the ware house in the farms. The supplier's chain and storage areas are very similar after statistical analysis. Consequently, no significance difference was statistically obtained amongst the two factors $\left(\chi^{2}=7.750 ; \mathrm{P}=0.188\right)$.

The number of sprayings before harvesting varies from farmers and may be less than two times (most frequent) or at greatest four times, depending on the type of disease that attacks the carrot or the frequency of rains. Farmers declared that weather influences the frequency of treatment and up to $94 \%$ of the agro-pesticide users, indicated that the frequency of treatment increases on rainy days. However, all the respondents stipulated that weather doesn't influence dosage. In these cases (number of treatment per crop cycle and the influence of weather on number of treatment and doses) no statistical significance difference was obtained amongst them $\left(\chi^{2}=5.125 ; \mathrm{p}=0.500\right)$. The fact is that they are related factors. These statistics remains similar to those of Number of the number of treatment before harvesting. All these parameters are linked and dependent.

3.5. Use of Protecting Equipment and the Management of Pesticide Containers after Use: The safety of pesticide users generally depends on protective clothing that they use during spraying. Table 5 shows the type of protecting equipment that farmers use and how they manage the pesticide containers after use. This will influence the environmental pollution and the health of pesticide sprayers.

Table 5: Type of protecting equipment used and the management of pesticides containers after use

\begin{tabular}{llll}
\hline Considerations & & $\begin{array}{l}\text { Frequen } \\
\text { cy }\end{array}$ & $\begin{array}{c}\text { Chi-square/ } \\
\text { p-value }\end{array}$ \\
\hline & Gloves & $12(23)$ & \\
& Rain boots & $18(35)$ & $\chi^{2}$-value $=3.258$ \\
Type of protecting equipment used & Face mask & $12(23)$ & p-value $=0.750$ \\
& Eye shades & $6(12)$ & \\
& Others & $4(8)$ & \\
& Dumping in the environment & $8(24)$ & $\chi^{2}$-value $=5.125 ;$ \\
Management of pesticide containers & Burning & $25(74)$ & p-value $=0.500$ \\
after use & Others & $1(3)$ & \\
Perception of symptoms of pesticide & Yes & $7(21)$ & $\chi^{2}$-value $=2.258$ \\
related illness & No & $27(79)$ & p-value $=0.750$ \\
& Eye reddening/itching & $1(14)$ & \\
Symptoms presented & Body weakness & $1(14)$ & $\chi^{2}$-value $=2.258$ \\
& Cough & $1(14)$ & p-value=0.750 \\
& Catarrh & $4(57)$ & \\
Carrot preferred for personal & Treated & $20(20)$ & $\chi^{2}$-value=2.258 \\
Consumption & Untreated & $80(80)$ & p-value=0.750 \\
\hline
\end{tabular}

During spraying, farmers put on rain boots, wear gloves and facemask, and at very low extent, wear eye shades, long sleeve dresses and rain coats during spraying. In managing the empty containers after spraying, since they cannot be reused because they are laminated carton, farmers generally burn them, dump them in the environment or in very few cases, are buried. No statistical significant difference was obtained among various ways of managing empty containers presented by farmers $\left(\chi^{2}=5.125 ; \mathrm{P}=0.500\right)$. This is because they manage empty containers with no conviction and can apply any method independently. 
Very few numbers of farmers who use pesticides acknowledged that they suffer from some pesticide related symptoms. The most frequent symptom is catarrh compared to eye irritation, body weakness and coughs which are rare among respondents. No statistical significance differences were gotten between various signs and symptoms in practicing safety measures $\left(\chi^{2}=3.258 ; \mathrm{p}=0.750\right)$.

3.6 Phytochemical composition of carrot: The chemical components were analyzed to evaluate the difference between the nutritive value of treated and untreated carrot and two phytochemicals (flavonoids and phenolic acids). Table 6 indicates various amounts of phenolic acids, flavonoids and total carbohydrates observed.

It can be drawn that the concentration of carbohydrates, flavonoids and phenols in the control sample are different from the sample grown with agrochemicals. Quantitative analysis of the different samples showed that the concentration of crude carbohydrate in the sample grown with agrochemicals was lesser than that in the control sample. The concentration of flavonoids in the control sample was greater than that in the sample grown with agrochemicals. This scenario is the same with phenols. Significant differences are obtained in all the cases between treated and untreated samples at $\mathrm{P} \leq 0.05$

Table 6: Chemical composition of carrot

\begin{tabular}{lccc}
\hline Samples & \multicolumn{3}{c}{ Concentrations of Components per 100 g } \\
\hline & Phenolic acid & Flavonoids & Total carbohydrates \\
& $(\mu \mathrm{g} \mathrm{AE} / 100 \mathrm{~g}$ of carrot $)$ & $(\mu \mathrm{g} \mathrm{GAE} / 100 \mathrm{~g}$ of carrot $)$ & $(\mathrm{mg} / 100 \mathrm{~g}$ of carrot $)$ \\
Treated carrot & $5.76 \pm 0.25^{\mathrm{b}}$ & $190.7 \pm 2.25^{\mathrm{b}}$ & $49.80 \pm 1.26^{\mathrm{a}}$ \\
Control (untreated) & $1.21 \pm 0.05^{\mathrm{a}}$ & $261.7 \pm 1.25^{\mathrm{a}}$ & $69.40 \pm 1.25^{\mathrm{b}}$ \\
\hline
\end{tabular}

Values in the same column with different upper scripts are significantly different at $\mathbf{P} \leq \mathbf{0 . 0 5}$

The means and the standard Deviation are the total mean obtained for each component during the study.

\section{DISCUSSIONS}

In Kedjom-Ketinguh locality, carrot cultivation is mostly done by men while their wives are mostly involved in the sale of carrots as was observed in their daily market during the study. Their low educational level is due to the fact that they grew up with their parents doing farming and most of them didn't show the need of furthering their education; as they got their farming experience from their parents which can be a good source of income. Similar observations were reported by Sonchieu et al. ${ }^{19}$ in Santa agricultural area among vegetable farmers.

The cultivation of carrot in upland area is because the soil is lighter and favors the growth of carrots since the favorable soil should be deep, well drained, sandy loam with a friable texture (Assured Food standard $^{20,21}$. Also, the majority of the farmers do their cultivation during the rainy season period which down land is still filled with water. The only variety of carrot cultivated in Kedjom-Ketinguh is technisem (orange rainbow carrot) and this so because it is the only type which its climatic conditions favor.

The majority of farmers do their planting in the month of March as a result of the availability of water because this month marks the beginning of the rainy season which is the farming season in that area. They consequently start harvesting in June indicating a crop cycle of 4 months. The crop is produced mostly for sale and this shows that consumption of this vegetables is not always usual among this population ${ }^{8,22}$. They are more interested in stable food (starchy food: cereals and tubers) which in most cases is accompanied by green leafy vegetable such as huckleberry ${ }^{8}$. 
The majority of the farmers have been using fertilizers for over 10 years to cultivate which means the usage of fertilizer to cultivate carrot is a routine which affects the quality of carrot as revealed by laboratory analysis in this study. However, the use of pesticides is minimized but the awareness about registered pesticides remains very poor and can be justified by the confidence given to supplier who at time advises on use instructions. The frequency of treatments or the total treatment remains satisfactory in the sense that the ethylene-bisdithiocarbamates (EBDC) used are moderately toxic and can degrade quickly within two weeks before harvesting ${ }^{8}$. However, the pre-harvesting period remains unclear according to farmer's opinions. This is not in line with observations of Sonchieu et al. ${ }^{19}$, on other vegetables cultivation in Santa agricultural area.

The reconditioning of pesticides to a quantity or volume before selling constitutes a dangerous exercise since Sonchieu et al. ${ }^{23}$ have proved that pesticides are poorly handled by sellers in the same Bamenda (supply zone) and many health issues were reported. The quantity bought is done according to the size of the farms and the period of cultivation. Generally, the small quantities are bought or burrowed when there is a shortage. However, seeds are bought from a local based research institute (IRAD: Institute of Research and Rural Development). From this institute, farmers can from frequently benefit for their counseling services on agronomical practices. The treatment given to containers (burning, burry of discarding in the environment) after use certainly contribute to environmental pollution and can be a threat to the ecosystem. This is in accordance with Kamga et al. ${ }^{24}$ and Sonchieu et al. ${ }^{19}$ following their report in Santa (agricultural area in the same Region). The use of protective clothing is very low as similarly observed by Usama et al. ${ }^{25}$ (2016). The prevalence of pesticide related symptoms can be associated to this fact. But surprisingly, they are aware of the fact that carrot treated with pesticides is not good for consumption, so they don't consume treated carrot to certain extent ${ }^{26}$.

Focusing on the nutritive value of carrot produced, the study confirms the fact that the treatment of crops with agrochemicals reduces their nutrient content ${ }^{27}$. A similar observation was reported by Akono et al. ${ }^{28}$ with concentration of phytochemicals in herbs. It is true that variation in concentration is also influenced by the period of planting that shows that dry season harvested carrot is sweeter than the one grown in rainy season because of water content. This observation is in line with Kjellenberg ${ }^{29}$ and Rani and Mallareddy ${ }^{13}$ Then, bioactive substances analyzed (flavonoids and phenols). This agrees with the study of Carlos and Dias ${ }^{7}$ which revealed that carrot is an important source of many phytochemicals but poorly produced.

The greater use of urea is due to its effectiveness in the cultivation of carrot and goat droppings is not commonly use because it requires grinding which is time consuming and less available.

\section{CONCLUSIONS}

In the locality of Kedjom-Ketinguh, agricultural practices when cropping carrot are based on the less use of agrochemicals. The use of pesticides is very moderate and carrot produced in this area can be considered safe for consumption. But residues of these pesticides need to be quantified for safety assessment as well as the maximum residues limit (MRL) is concerned. Safety measures applied remain very poor and cannot give a guaranty for users to avoid pesticide related diseases. Management of used containers seems to be a risk for the environment. A deep study can be extended to other crops and on analysis of body fluid of farmers to confirm the safety of carrot produced.

\section{ACKNOWLEDGMENT}

Authors thank the laboratory of Biochemistry of the Faculty of Science, The University of Bamenda, which facilitated the laboratory analyses. 


\section{AUTHORS' CONTRIBUTIONS}

Sonchieu Jean, supervised the work and writes the paper. Feh Watad Gilbert and Fru Nsoh John collected data from the field and carried out the laboratory analyses.

\section{CONFLICT OF INTEREST}

Authors declare that there no conflict of interest concerning this paper.

\section{REFERENCES}

1. C.K. Winter, and S.F. Davis, Journal of Food Science, 2006, 1 (9), 117-124.

2. S. Pehme, A. Luik, and P. Liivaauk, Estonian consumer's attitudes to organic food, 2007, Available at: http:// orgprints.org/9930/, 27 February 2017.

3. A. D. Dangour, S .K. Dodhia, A. Hayter, E. Allen, K. Lock, and R. Uauy, American Journal of Clinical Nutrition, 2009, 90, 680-685.

4. G. M. C. Matallana, M.J. Martinez-Tome. and M.E. TorijaIsasa, Food Additives and Contaminants: Part B, 2010, 1, 19-29.

5. Ministry of Agriculture and Rural Development (MINADER) (2012).AGRI-STAT: Annuaire des Statistiques du Secteur Agricole Campagnes 2009 et 2010. Yaoundé Cameroon.

6. F.B. Essing, What's in a Family? The Apiaceae. Florida Gardening, 2013, 18, 36-37.

7. J. Carlos, and S. Dias, Food and Nutrition Sciences, 2014, 5, 2147-2156, doi: $0.4236 /$ fns.2014.522227.

8. G. A. Asongwe, B. P.K. Yerima and A. S. Tening, International Journal of Current Microbiology and Applied Sciences, 2014, 3(12), 682-700.

9. K.D. Sharma, S. KarKi, S. ThaKurn, and S. Attri, Journal of Food Science Technology, 2012, 49(1), 22-32. DOI: 10.1007/s13197-011-0310-7.

10. J. Fiedor, and K. Burda, Nutriens, 2014, 6, 466-488, doi: 10.3390/nu6020466.

11. T. Tanaka, M. Shnimizu, and H. Moriwaki, Molecules, 2012, 17, 3202-3242, doi: 10.3390/molecules17033202.

12. L. Kjellenberg, E. Johansson and K.E. Gustavsson, Journal of Agriculture and Food Chemistry, 2010, 24, 58 (22), 11703-11718.

13. N. S. Rani and K. Mallareddy, Karnataka Journal of Agricultural Sciences, 2007, 20 (3), $686-688$.

14. WHO, Public Health Impact of Pesticides Used in Agriculture.WHO Library Cataloguing in Publication Data, 2015.

15. WHO, Global Database on Vitamin A Deficiency: The Vitamin A Deficiency database includes data by country based on xerophthalmia and/or serum or plasma retinol concentration, Cameroon, 2007.

16. S. N. Balgah, Journal of Architecture Engeneering and Technology, 2017, 6(2), 204. DOI: 10.4172/2168-9717.1000204

17. S. Kamtekar, V. Keer, V. Patil , Journal of Applied Pharmacology Science,2014, 4(09): 061-065.

18. F.R.G. Tchouya and A.E. Nantia, Journal of Pharmacognitive Phytochemistry, 2015, 3(5), 192-195. 
19. J. Sonchieu, M.B. Ngassoum, A.E. Nantia, P.S. Laxman, SSRG International Journal of Agriculture \& Environmental Science, 2017, 4 (2):39-46.

20. Assured Food standard, 2018. Crop Module: Carrots. Version 3.2 (Crop Risk Category 2), 20 pages. (URL: www.redtractor.org.uk, accessed on October 2018.

21. A. Shika, and W. Doug, Carrots - Post-Harvest Handling and Storage. Facts sheet. Department of Plant Sciences, University of Saskatchewan, 2001, 2.

22. S. Adam, Sustainability, 2014, 6, 1868-1895; doi:10.3390/su6041868

23. J. Sonchieu, E. N. Akono, C.T. Ngwamitang, M.B. Ngassoum, Environmental Science and Pollution Research, 2018, 25, 9454-9460

24. R, C. Kamga, A. Kouamé, T. Atangana, Chagomoka, and R. Ndango, Journal of Horticulture Research, 2013, 21(1), 99-106.

25. Usama, I. A., M. A. Nermeen, S.S. Mohamed, International Journal of PharmTech Research, 2016, 9(9), 121-129.

26. Jelena, J., Ć. Jelena, B. Marija, Š. Danijela, P. Milka, and Ž. B. Milan, Research in Agriculture, 2018, 3(1), 104-115. doi:10.22158/ra.v3n1p1.

27. Hochmuth, G. J., J. D. Brecht, and M. J. Bassett, Horticulture Technology, 2006, 16 (2), $270-276$.

28. E.N. Akono, M.G. David, P. T.M. Faustin , J. Sonchieu, P. F. Moundipae, A. M. GarciaCampanab, and L. Gamiz-Gracia, Analytical letters, 2017, 50(9), 1397-1409.

29. L. Kjellenberg, Sweet and Bitter Taste in Organic carrot. Paper at the Faculty of Landscape Planning, Horticultural and Agricultural Science. Swedish University of Agricultural sciences, 2007.

\section{* Corresponding Author: Sonchieu Jean}

Department of Social Economy and Family Management, Higher Technical Teacher Training College, The University of Bamenda, PO. Box 39 Bamenda, Cameroon 